\title{
Uso do açúcar na cicatrização de úlceras de pressão
}

\author{
Eduardo da Rosa Brandão*, Thaís Fronczak*, Andersom Ricardo Fréz, M.Sc.**, \\ Marinêz Boeing Ruaro***, João Afonso Ruaro, M.Sc.***
}

${ }^{*}$ Fisioterapeuta pela Faculdade Anglo-Americano/FAA, **Docente da Universidade Estadual do Centro-Oeste/UNICENTRO, ***Docente da Universidade Federal do Rio Grande do Norte/UFRN

\section{Resumo}

Este estudo teve o objetivo de avaliar os efeitos da aplicação de açúcar cristal em úlceras de pressão. Três úlceras foram acompanhadas como controle e três submetidas ao tratamento com açúcar aplicado na úlcera de pressão 4 vezes ao dia, por 28 dias. Foram realizadas análises microbiológicas laboratoriais, avaliação através da escala de úlceras de pressão e mensuradas as áreas das úlceras. Não se observou diferença significativa $(\mathrm{p}<0,05)$ nas áreas das úlceras. Foram encontradas bactérias do tipo Staphylococcus sp. em todas as amostras. Na escala de cicatrização observou-se melhora na qualidade do tecido e de seu exsudato, em ambos os grupos. Assim, o uso de açúcar não se mostrou um método significativo na cicatrização de úlceras de pressão.

Palavras-chave: açúcar, úlceras de pressão, cicatrização de feridas.

\section{Abstract}

\section{Sugar in pressure ulcers healing}

The purpose of this study was to evaluate the crystal sugar paste effects in pressure ulcers. Three pressure ulcers were studied as control group and three were treated with crystal sugar paste. The sugar paste was applied on the wound four times a day for 28 days. Microbiological lab analysis, ulcer area measurement and evaluation with pressure ulcer scale were done before and after treatment. Significant differences were not found $(\mathrm{p}<0.05)$ in ulcer area. Staphylococcus sp. were found in all the collected samples. The healing scale analysis showed better tissue and exudate quality in both groups. The sugar use was not a significant method in the healing process of pressure ulcers.

Key-words: sugar, pressure ulcer, wound healing.

\section{Resumen}

\section{La utilización del azúcar en la cicatrización de las úlceras de presión}

Este estudio tiene como objetivo evaluar los efectos de la aplicación del azúcar cristal en las ulceras de presión. Tres úlceras fueran acompañadas como control y tres sometidas al tratamiento con azúcar aplicado en la ulcera de presión 4 veces al día, por un periodo de 28 días. Fueron realizadas análisis microbiológicas y de laboratorio, evaluación a través de la escala de úlceras de presión y mensuradas las áreas de las ulceras. No se observó significativa diferencia $(\mathrm{p}>0,05)$ en las áreas de las úlceras. Fueron encontradas bacterias del tipo Staphylococus sp. en todas las muestras. En la escala de cicatrización observase mejoría en la calidad del tejido y de su exudado, en ambos los grupos. Así, la utilización del azúcar no se mostró un método significativo en la cicatrización de las úlceras de presión.

Palabras-clave: azúcar, úlcera por presión, cicatrización de heridas. 


\section{Introdução}

Os pacientes que permanecem por longos períodos acamados em hospitais, ou mesmo em suas residências, possuem alta probabilidade de formaçáo de úlcera de pressão $[1,2]$. Estas são definidas como uma lesão cutânea, provocada pela pressão exercida nos tecidos subcutâneos pelas proeminências ósseas e por objetos em contato com o corpo. Podem se relacionar à sua etiologia alguns fatores extrínsecos, como: pressão, cisalhamento, fricção e umidade; e intrínsecos: idade, fatores nutricionais e doenças crônicas $[1,3,4]$.

Os indivíduos mais suscetíveis à formação de uma úlcera de pressão são aqueles que apresentam algum tipo de hipomobilidade, algum nível de lesão medular, idosos e/ou indivíduos cronicamente doentes, principalmente os mal nutridos $[5,6]$.

A classificação das úlceras de pressão, segundo o Centro Nacional de Dados sobre a Lesão Medular e do Ministério da Saúde, é descrita em: grau I - as lesôes são limitadas à epiderme e derme superficial; grau II - envolvem a pele em espessura total e tecido subcutâneo; grau III - comprometimento da epiderme, derme e as lesóes se estendem até o plano muscular; grau IV - destruição de todos os tecidos [1,7]. Quanto à localização, 32,5\% das úlceras de pressão são sacrais, $32,5 \%$ trocantéricas, $15,6 \%$ isquiáticas, 5,2\% em joelho, 3,9\% em calcâneo, $2,6 \%$ em perna, ombro e regiáo lombar e $1,3 \%$ em região torácica e occipital [1].

O processo de cicatrização das úlceras de pressão só se torna completo quando a resposta inflamatória estiver controlada, e não houver a presença de detritos necróticos, permitindo, assim, o crescimento do tecido de granulação [8]. Para a remoção deste tecido necrótico é utilizada a técnica de desbridamento. Esta possui vantagens e desvantagens, sendo o método escolhido dependente da condição e necessidade do paciente $[2,3]$.

É possível a realizaçáo do desbridamento de forma alternativa e de fácil execução, através da aplicação de açúcar no tratamento de feridas. $\mathrm{O}$ açúcar atua diminuindo o odor, inibindo o crescimento bacteriano, reduzindo, o edema e o $\mathrm{pH}$ no local da ferida. Também dilata pequenos vasos, melhora a nutrição do tecido, estimula o tecido de granulação (pela irritação local) e coopera, assim, para o bom crescimento do tecido de reepitelização $[2,3]$.

Neste contexto, considerando a capacidade do açúcar em acelerar a cicatrização e a viabilidade econômica para várias camadas sociais, devido ao baixo custo deste tratamento, este trabalho teve como objetivo avaliar a influência do açúcar cristal na cicatrização de úlceras de pressão, considerando-se a área, a presença de patógenos e a qualidade do tecido e seu exsudato.

\section{Material e métodos}

A pesquisa foi aprovada, de acordo com a Resoluçáo 196/96 do Conselho Nacional de Saúde, pelo Comitê de Ética em Pesquisa da Faculdade Assis Gurgacz (CEP/FAG) sob parecer 012/2008. A amostra foi composta por 6 úlceras de pressão, sendo aplicado o protocolo de tratamento com açúcar cristal (GA) em 3 úlceras de pressão; e as outras acompanhadas como controle (GC). Não se considerou o número de úlceras por paciente. Os pacientes faziam parte do Programa de Internamento Domiciliar (PID) disponibilizado pela Prefeitura Municipal de Foz do Iguaçu ou estavam em tratamento na Clínica-Escola de Fisioterapia da Faculdade Anglo-Americano/FAA. Estes pacientes apresentavam idade entre 20 e 60 anos e, obrigatoriamente, náo eram portadores de diabetes mellitus.

\section{Procedimento metodológico}

O protocolo foi aplicado de forma domiciliar. O cuidador responsável recebeu orientaçáo dos pesquisadores e folheto explicativo sobre a aplicação da técnica. A cada troca de curativo o paciente era posicionado em decúbito que facilitasse o acesso à úlcera de pressão Realizava-se a limpeza local com jatos de soro fisiológico em temperatura ambiente. Quando havia a presença de tecido necrótico exercia-se maior pressão na aplicação do jato, e quando removido totalmente era exercida menor pressão, para evitar lesão no tecido de granulação.

A pasta de açúcar preparada continha $98 \%$ de açúcar cristal e $2 \%$ de água destilada, fornecidos pelos pesquisadores. A medida utilizada para a preparação, sem utilização da balança [9], consistia em 01 copo americano de açúcar cristal $(140 \mathrm{~g})$, para uma colher de café $(2,8 \mathrm{ml})$ de água destilada. A mistura era realizada em recipiente plástico ou de vidro, com o auxílio de colher plástica, sempre preparada na hora da utilização, para melhor aproveitamento das suas propriedades. A pasta foi aplicada no local da ferida, cobrindo toda a extensão da lesão, 4 vezes ao dia, durante a troca de curativos a cada 6 horas. O protocolo foi aplicado por 28 dias. No GC foi 
realizada apenas a limpeza com soro fisiológico e trocado os curativos na mesma frequência.

As avaliaçóes foram realizadas no primeiro e no último dia de aplicação. Amostras da úlcera foram coletadas com swab e submetidas à análise microbiológica laboratorial. As amostras foram cultivadas em ágar manitol; após 24 horas, foi realizada a prova de catalase e Gram.

A área, o tipo do tecido de cicatrizaçáo e a quantidade de exsudato das úlceras foram avaliados e qualificados através da escala de cicatrizaçáo da úlcera de pressão [10]. A área da úlcera foi mensurada através de fotografia, posicionando uma referência de $1 \mathrm{~cm}$ próximo da borda, e a imagem analisada e quantificada pelo software Image Tools. O tipo de tecido foi classificado em 5 categorias: cicatrizado, epitelizado, de granulação, desvitalizado e necrótico. Já a quantidade de exsudato foi categorizada da seguinte forma: nenhum, escasso, moderado ou abundante.

Para a verificação da aplicação do protocolo foi realizada visita semanal no domicílio do paciente.

\section{Análise dos dados}

A análise estatística foi realizada através do software Graph-Pad Instat versão 3.05. Os dados são apresentados em média e desvio padrão, após análise de normalidade pelo teste de Shapiro-Wilks, para os dados de pré e pós-aplicação. Para análise intergrupos foi utilizado teste $t$ de Student, sendo comparados: diferença pré e pós-aplicação no GA e no GC.

\section{Resultados}

$\mathrm{Na}$ análise do efeito das técnicas propostas para a cicatrização das úlceras de pressão, compararam-se as áreas pré e pós-tratamento e a diferença entre elas (Tabelas I e II). Ao submeter os resultados, pré e pós-aplicação, a análise estatísticas intragrupo não foram encontrados resultados significativos, sendo $\mathrm{p}$ $=0,3660$ no GA e $\mathrm{p}=0,2175$ no GC. Considerou-se estatisticamente significativo $\mathrm{p}<0,05$, segundo teste $t$ de Student. A comparação da diferença de área pré e pós-aplicação intergrupos também não foi significativa, sendo $\mathrm{p}=0,5504$.

Nos exames microbiológicos laboratoriais foram encontrados, em todas as amostras, bactérias do tipo Staphylococcus sp. Não foram identificados o tipo de bactéria, podendo ser Staphylococcus aureus ou Staphylococcus epidermidis, sendo o primeiro patológico, e o segundo componente da flora bacteriana natural do corpo humano.

Tabela I - Análise intragrupo das diferenças das áreas das úlceras pré e pós-aplicação, GA $\left(\mathrm{em} \mathrm{cm}^{2}\right)$.

\begin{tabular}{ccccc}
\hline Úlcera & Pré & Pós & $\Delta$ & $\% \Delta^{*}$ \\
\hline 1 & 1,22 & 0,89 & $-0,33$ & $-27,04 \%$ \\
2 & 2,75 & 2,37 & $-0,38$ & $-13,81 \%$ \\
3 & 42,34 & 35,30 & $-7,04$ & $-16,62 \%$ \\
\hline
\end{tabular}

$*_{p}=0,3660$

Tabela II - Análise intragrupo das diferenças das áreas das úlceras pré e pós-aplicação, GC $\left(\mathrm{em} \mathrm{cm}^{2}\right)$.

\begin{tabular}{lcccc}
\hline Úlcera & Pré & Pós & $\Delta$ & $\% \Delta *$ \\
\hline 4 & 3,28 & 1,78 & $-1,50$ & $-45,73 \%$ \\
5 & 6,61 & 3,10 & $-3,51$ & $-53,10 \%$ \\
6 & 1,31 & 3,50 & 2,19 & $167,20 \%$ \\
\hline${ }^{*} \mathrm{p}=0,2175$ & & & &
\end{tabular}

Através da escala de cicatrização da úlcera de pressão onde foram avaliadas a qualidade do tecido e a qualidade do exsudato presente na úlcera foi possível observar melhora na qualidade do tecido e de seu exsudato, em ambos os grupos, o que favorece e acelera o processo de cicatrização local (Tabelas III e IV).

Tabela III - Escala de cicatrização da úlcera de pressão, GA.

\begin{tabular}{lcccc}
\hline \multirow{2}{*}{ Úlcera } & \multicolumn{2}{c}{ Tipo de tecido } & \multicolumn{2}{c}{ Tipo de exsudato } \\
\cline { 2 - 5 } & Pré & Pós & Pré & Pós \\
\hline 1 & 2 & 1 & 1 & 1 \\
2 & 2 & 2 & 2 & 1 \\
3 & 3 & 1 & 3 & 1 \\
\hline
\end{tabular}

Tabela IV - Escala de cicatrização da úlcera de pressão, GC.

\begin{tabular}{ccccc}
\hline \multirow{2}{*}{ Úlcera } & \multicolumn{2}{c}{ Tipo de tecido } & \multicolumn{2}{c}{ Tipo de exsudato } \\
\cline { 2 - 5 } & Pré & Pós & Pré & Pós \\
\hline 4 & 3 & 1 & 0 & 0 \\
5 & 3 & 2 & 2 & 3 \\
6 & 3 & 3 & 1 & 1 \\
\hline
\end{tabular}

Discussão

Segundo Rocha et al. [11], cerca de 34\% dos lesados medulares desenvolvem úlceras de pressão durante primeiro período de internamento, 30$40 \%$ nos primeiros 5 anos de lesão, e $50-80 \%$ pelo menos uma vez na vida, podendo chegar a $100 \%$ [1]. No presente estudo, $90 \%$ da amostra de úlceras de pressão foram observadas em indivíduos lesados medulares. 
Mesmo com os avanços da ciência fitoterápica ainda há muitas controvérsias sobre a utilização de tratamentos alternativos como a aplicação de açúcar cristal em úlceras infectadas. Pois, se levanta a hipótese destas serem colonizadas ou não. Zanon e Neves [12] reforçam que as feridas são colonizadas, porém poucas supuram, e em casos assim a sobrevivência e a multiplicação bacteriana dependem do número de micro-organismos invasores. No entanto, existem micro-organismos como: Pseudomonas aeruginosa, Klebsiela sp, Proteus sp e Streptococcus sp que estâo presentes na flora microbiana do indivíduo portador da úlcera.

O açúcar apresenta bons resultados no tratamento de úlceras infectadas, devido a sua ação bactericida, bacteriostática e antisséptica. Estas ações são explicadas através do efeito osmótico desenvolvido pelo açúcar na membrana e parede celular bacteriana, sendo eficaz no tratamento antimicrobiano contra Staphylococcus, Streptococcus, Enterobacter, Escherichia coli, Klebsiela sp, Pseudomonas e Serratia [12,14,15].

Segundo Chirife e Herszage [16], todos os organismos vivos necessitam de água para a sua sobrevivência. A utilização do açúcar cristal altera esta disponibilidade de água na úlcera a níveis suficientes para impossibilitar o crescimento de micro-organismos. O Staphylococcus aureus é o germe patogênico mais resistente a pouca disponibilidade de água, sendo assim, se ele não puder crescer e se reproduzir no leito da úlcera, dificilmente outros micro-organismos menos exigentes, como Pseudomonas aeruginosa e Escherichia coli, crescerão, por isso o açúcar é um antimicrobiano universal.

Forrest [17] concorda que o efeito bactericida do açúcar ocorre predominantemente pela ação osmótica, acrescentando ainda que ele não desidrata apenas as bactérias, como também células epiteliais, macrófagos, e fibroblastos na margem da ferida. Dessa forma, reduz a migração e a divisão das células, potencializando, a cicatrização. No entanto, apesar de concordar que o açúcar é um tratamento tópico barato e disponível, discorda plenamente da teoria de Chirife e Herszage [16], de que o açúcar seja um antimicrobiano universal. Afirma ser complicado transferir resultados obtidos em laboratórios para situaçóes clínicas, e ainda, que úlceras infectadas por Staphylococcus podem ser tratadas na maioria das vezes com desbridamento cirúrgico e drenagens, não sendo necessária a utilização de agentes tópicos.

Em relação às análises laboratoriais realizadas, onde foi encontrado Staphylococcus sp em todas as amostras, conclui-se que não houve efeito bactericida contra este micro-organismo, porém, o não aparecimento de outras espécies bacterianas pode indicar o efeito bacteriostático da aplicação da pasta de açúcar cristal.

Estudos sobre a utilização de açúcar em feridas limpas sugerem a troca de curativos a cada 4 horas, e para as infectadas a cada 2 horas [18]. Já Haddad et al. [15] realizaram as trocas a cada 8 horas até o surgimento de tecido de granulaçáo; a partir deste período trocas a cada 12 horas, até o aparecimento de tecido epitelial nas bordas das úlceras e redução da profundidade da lesáo; e neste ponto passaram a realizar as trocas a cada 24 horas. No presente estudo foi utilizado um intervalo de 6 horas entre cada troca de curativo, pois acima deste tempo estimou-se uma diminuição da concentração do açúcar, proporcionando, assim, um meio propício para o desenvolvimento de micro-organismos, ao invés de estimular as propriedades bactericidas do açúcar. Porém, Chirife et al. [14] relataram que, com o uso do açúcar, após 10 horas a osmolaridade continua sendo eficaz para inibir o crescimento da maioria dos microrganismos patógenos. Sugerindo assim, que as trocas possam ser feitas com intervalos superiores a 10 horas. Já Cavazana et al. [19] realizaram as trocas de curativos a cada 24 horas e não observaram prejuízos para a cicatrizaçáo.

Dor e mau odor das úlceras são descritos como os maiores desconfortos dos pacientes [5, $13,20,21]$. Tais relatos não foram observados nesta pesquisa. Isso pode ser explicado pelas alteraçóes de sensibilidade portadas pelos pacientes da amostra. Castro et al. [13] ainda citam que na presença de mau odor após o início do tratamento com açúcar cristal foi observado que em poucos dias o mesmo desapareceu. É possível explicar este fenômeno, pois como com a presença de açúcar no leito da úlcera estimularam as bactérias ali existentes a utilizar glicose para o seu metabolismo, produzindo assim ácido láctico, uma substância que não apresenta odor.

Quanto à área da úlcera, semelhante ao presente trabalho, Cavazana et al. [19] em seu estudo sobre uso do açúcar na cicatrização, também observaram que o percentual de redução de feridas que o uso do açúcar propicia não é satisfatório.

Utilizou-se como critério de exclusão sujeitos diabéticos, pois além de terem maior dificuldade de cicatrização [22], considerou-se prudente evitar uma possível sobrecarga glicêmica com a aplicação direta de açúcar na úlcera e por consequência na corrente sanguínea. Porém, Shi et al. [23] demonstraram que o uso de $70 \%$ de açúcar e $3 \%$ de povidine-iodine 
acelera a reepitelização de úlceras em ratas diabéticas, mesmo as infectadas com Staphylococcus aureus. E ainda Herszage et al. [24], após aplicação de sacarose sobre lesóes supurativas, observaram que a cicatrização evoluiu rapidamente e com desaparecimento de agentes patógenos, mesmo nos indivíduos diabéticos.

Cavazana et al. [19] afirmam que o açúcar não apenas promove a cicatrização de feridas, mas a modulação da resposta inflamatória celular. Kössi et al. [25], em seu estudo sobre o efeito de diferentes concentraçóes de soluçóes contendo açúcar, observaram que estas não modificam qualitativamente $o$ tecido de granulação. Porém, observou-se, através da escala de cicatrização da úlcera de pressão, melhora na qualidade do tecido e de seu exsudato, em ambos os grupos. Mesmo no GC, sugerindo que, apenas com a troca de curativos mais frequente e o aumento de cuidados, o leito da úlcera se manteve mais limpo e preparado para o processo de cicatrizaçáo.

\section{Conclusão}

Possivelmente pelo tamanho reduzido da amostra os resultados encontrados náo mostram a utilização de açúcar cristal como um método significativo na cicatrização de úlceras de pressão. Porém, observou-se que o aumento dos cuidados propicia melhores condições de cicatrização, sendo ou não associado a agentes tópicos.

\section{Referências}

1. Costa MP, Sturtz G, Costa FPP, Ferreira MC, Barros Filho TEP. Epidemiologia e tratamentos das úlceras de pressão: experiência com 77 casos. Acta Ortop Bras 2005;13(3):124-33.

2. Pieper B, Caliri MHL. Nontraditional wound care: a review of the evidence for the use of sugar, papaya/ papain, and fatty acids. J WOCN 2003;30(4):175-83.

3. Blanes L, Duarte IS, Calil JA, Ferreira LM. Avaliação clínica e epidemiológica das úlceras por pressão em pacientes internados no Hospital São Paulo. Rev Assoc Med Bras 2004;50(2):182-7.

4. Giaretta VMA, Posso MBS. Úlceras por pressão: determinação do tempo médio de sinais iniciais em idosos sadios na posição supina em colchão hospitalar. Arq Med ABC 2005;30(1):39-43.

5. Spilsbury K, Nelson A, Cullum N, Iglesias C, Nixon J, Mason S. Pressure ulcers and their treatment and effects on quality of life: hospital inpatient perspectives. J Advanced Nurs 2007;57(5):494-504.

6. Shahin ESM, Dassen T, Halfens RJG. Pressure ulcer prevalence in intensive care patients: a cross-sectional study. J Evaluation Clinical Practice 2008;14:563-8.

7. Ministério da Saúde. Secretária de políticas de saúde. Departamento de açáo básica. Manual de condutas para úlceras neurotróficas e traumáticas. Brasília: Ministério da Saúde; 2002.

8. Rocha RPA, Gurjão WS, Brito Junior LC. Avaliação morfológica da cicatrização de lesôes ulcerativas assépticas tratadas com soluçôes de papaína. In: VII Congresso Virtual Hipanoamericano de Anatomia patológica y I Congresso de Preparaciones Virtuales por Internet; 2005,01-31/10.

9. Tabela de Medidas. Algumas dicas para se conhecer medidas sem a utilização de balança. Disponível em: URL: http://www.see.go.gov.br/educacao/servicos/ merendaescolar/pdf/tabela.pdf

10. Ferreira PL, Miguéns C, Gouveia J, Furtado K. Mediçáo da qualidade de vida de doentes com feridas crônicas: a escala de cicatrização da úlcera de pressão e o esquema Cardiff de impacto da ferida. Nursing 2007;221:32-41.

11. Rocha JA, Miranda MJ, Andrade MJ. Abordagem terapêutica das úlceras de pressão - intervenção baseadas na evidência. Acta Med Port 2006;19:29-38.

12. Zanon U, Neves J. Infecçôes hospitalares: prevenção, diagnóstico e tratamento. Rio de Janeiro: Medsi; 1987.

13. Castro SZ, Franco MJ, Acosta YR. Experiencia en la cura de úlceras por presión con sacarosa. Rev Cuba Enferm 2006;22(3):1-9.

14. Chirife J, Herszage L, Joseph A, Kohn ES. In vitro study of bacterial inhibition in concentrated sugar solutions: microbiological basis for the use of sugar in treating infected wounds. Antimicrob Agents Chemother 1983;23:766-73.

15. Haddad MCL, Bruschi LC, Martins EAP. Influência do açúcar no processo de cicatrização de incisóes cirúrgicas infectadas. Rev Latinoam Enferm 2000;8(1):57-65.

16. Chirife J, Herszage L. Sugar for infected wounds. Lancet 1982;1(8276):861-910.

17. Forrest RD. Sugar in the wound. Lancet 1982;1(861).

18. Écheli CSB, Busato CR. Tratamento tópico de úlcera de estase venosa - proposta para padronizaçáo. Publ UEPG Cienc Biol Saúde 2006;12(1):7-14.

19. Cavazana WC, Biondo-Simóes MLPB, Yoshii SO, Bersani-Amado CA, Cuman RKN. Açúcar (sacarose) e triglicerídeos de cadeia média com ácidos graxos essenciais no tratamento de feridas cutâneas: estudo experimental em ratos. An Bras Dermatol 2009;84(3):229-36.

20. De Laat E, Scholte RWJ, Van Achterberg T. Pressure ulcers: diagnostics and interventions aimed at wound-related complaints: a review of the literature. J Clinical Nursing 2005;14:464-72.

21. Hopkins A, Dealey C, Bale S, Defloor T, Worboys F. Patient stories of living with a pressure ulcer. J Advanced Nursing 2006;56(4):345-53.

22. Greghi SLA, Brito MCT, Oliveira MR, Guimarães MCM. Relaçáo entre diabetes mellitus e doença periodontal. Rev APCD 2002;56(4):265-9.

23. Shi CM, Nakao H, Yamazaki M, Tsoboi R, Ogawa $\mathrm{H}$. Mixture of sugar and povidine-iodine stimulates healing of MRSA-infected skin ulcers on $\mathrm{dB} / \mathrm{db}$ mice. Arch Dermatol Res 2007;299:449-56.

24. Herszage L, Montenegro J, Joseph A. Traitement des plaies suppurees por applications de ssaccharose. Nouv Presse Med 1982;12:940.

25. Kössi JA, Ekfors TO, Aaltonen V, Laato M. Sucrose has no beneficial effects on wound healing in rats. Eur J Surg 2000;166:818-22. 